\title{
First year university student engagement using digital curation and career goal setting
}

\author{
Amy Antonio $^{\mathrm{a} *}$ and David Tuffley ${ }^{\mathrm{b}}$ \\ ${ }^{a}$ Australian Digital Futures Institute, University of Southern Queensland, Brisbane, Queensland, \\ Australia; ${ }^{b}$ School of Information and Communication Technology, Griffith University, Brisbane, \\ Queensland, Australia
}

(Received 23 April 2015; final version received 20 September 2015)

\begin{abstract}
The engagement of students is one of the most pressing issues facing higher education in the 21 st century. Around the world, participation rates in tertiary education are on the rise and one of the key challenges facing educators is finding ways to engage these students. We present the results of a project that assesses the impact of an engagement strategy in which a cohort of students entering their first year of university (1) establish and maintain a clear goal of their ideal future career and (2) make use of a web-based digital curation tool to research and present their findings. The results demonstrate the effectiveness of the strategy, which could arguably be applied to a broad range of disciplines given that the majority of students today are technologically literate.
\end{abstract}

Keywords: engagement; goal setting; digital curation; higher education

\section{Introduction}

The transition from school to university has proven to be particularly difficult for many new students. The challenges are even greater when the student is the first in their family to attend university (Olson 2013). During their high school years, students are primarily directed by external authority figures. The transition from high school to university requires a shift from an external to an internal locus of control (Astin 1999). University life is a threat to familiar ways of knowing, both in terms of life adjustments, such as moving away from home for the first time and, more importantly, in terms of how students learn. Student engagement strategies have thus emerged as an increasingly important issue in higher education. Orthner et al. (2012, p. 27) argue that in order 'for students to perform well ... they must believe that their focus on education will pay dividends for them now and in the future'. It is therefore imperative for educators to help students identify their interests, values, aptitudes and beliefs so that they can make sound decisions about their career plans (Lessard et al. 2014). Building on the above premise, this paper describes the development of a goalsetting strategy that was trialled with a cohort of first year university students.

\footnotetext{
*Corresponding author. Email: Amy.Antonio@usq.edu.au Responsible Editor: Peter Reed, The University of Liverpool, United Kingdom.
} 


\section{A. Antonio and D. Tuffley}

\section{Academic relevancy and goal setting}

There are many reasons that influence students' decision to stay beyond the first year; however, according to the Australasian Survey of Student Engagement (Radloff 2012), boredom is cited as the primary reason that contributes to students' decision to quit their course. In order to improve student success, which can be understood as students' completing their course and attaining employment, educators need to engage students by encouraging them to imagine beyond the immediate goal of getting through a class.

Engagement is influenced to some degree by the students' perception of how relevant the university experience is in terms of their career aspirations and plans for the future. Students are more likely to succeed if (1) they connect with a plan of study that aligns with their interests and abilities and (2) if they are committed to their academic goals (Tuffley and Antonio 2013). Existing research suggests that students who engage with their education and consider school a valuable experience are more likely to achieve academically. Perry (2008) argues that students who believe their education is relevant and that it is assisting them to achieve future goals are more likely to perform well and graduate. As such, Orthner (2007) notes that one of the many teaching strategies employed in school reform efforts involves augmenting the relevance of the curriculum so that students can establish a link between the content they are learning and their expectations for the future.

Building on this premise, significant attention has been given to promoting school engagement to improve students' attention, particularly in secondary school settings. Research indicates that student career exploration can have a positive effect on school engagement. Students in school-to-work programmes consistently exhibit higher psycho-social school engagement than students who are not participating in career exploration (Orthner et al. 2012; Oyserman 2008; Perry, Liu, and Pabian 2010).

Greene et al. (2004) sampled 220 students from a suburban high school to assess whether or not academic relevancy influenced student engagement. They found that perceptions of relevance of in-class work were instrumental for future success and enhanced academic engagement. Andriessen, Phalet, and Lens (2006) similarly compared the effects of perceived instrumentality, another variable used to represent the relevance of schoolwork to future goals, and motivation among students. The results suggested that when students perceive the usefulness of school for their future, it could potentially serve as a protective factor against academic disengagement. In addition to academic relevancy, Tan (2007) found that students are engaged by future-driven assessments. Such tasks connect performance and achievement in the present to goals for the future. Students thus see the assessment of their current performance as a step towards their professional future. That is, the students can start to envision how their skills and knowledge have applicability beyond the classroom. The notion of future-driven assessment closely resembles Locke and Latham's (1990) goal-setting theory. When individuals set goals, they are encouraged to find strategies for how a goal can be achieved and, thus, direct their effort towards relevant activities. This theory was borne out by Arnold and Mackenzie Davey (1992) who found that when individuals' perceived that tasks did not require utilisation of their skills, they were less motivated and tended to direct their energy towards irrelevant, non-work related activities.

Research with university students has tended to focus on either the external/ extrinsic factors or internal/intrinsic factors that contribute to student engagement. 
While involvement with other students, lecturers and the university community constitute the so-called external or extrinsic factors, this article is interested in the internal factors, such as goal setting, that facilitate engagement and, as such, studies looking at external factors have not been considered here. A number of studies have examined the relationship between students' self-efficacy [an individual's belief in his or her ability to complete a set of tasks to obtain a specific outcome (Bandura 1982)] and their educational and career goals. Career goals have been linked to both student perceptions of self-esteem and educational self-efficacy.

According to Chiu (1990), adolescents with specific career goals have higher self-esteem than those without career goals, while Nauta (1997) similarly found that, among women, self-esteem predicted career aspirations in math, science and engineering majors. Hull-Blanks et al. (2005) looked at the relationship between selfefficacy and school and career commitment among first semester college freshmen. In this study, relationships between types of career goals and retention-related factors were examined. They found that students with job-related career goals were more likely to persist with their education than those without career goals. This suggests that having a goal (long range goals appear to be particularly helpful for persistence) that is dependent on the successful completion of one's education is likely to motivate students to continue in the face of challenges. In a recent study by Wright, JenkinsGuarnieri, and Murdock (2012), the relationship between self-belief, success and persistence was explored. This study investigated how college students' self-efficacy related to persistence and academic success in the critical first year at university. A sample of 401 undergraduate students completed the College Self-Efficacy Inventory, which revealed that increased levels of self-efficacy at the end of the first semester were associated with greater odds of persisting into the next semester and of being academically successful.

\section{Technology-enhanced learning}

Other strategies have emphasised the importance of technology-enhanced learning experiences for cultivating student engagement. A number of researchers have explored how particular Web 2.0 technologies, particularly social networking technologies, can be used to create interactive and engaging learning experiences (Antonio and Tuffley 2014; Ebner et al. 2010; Junco, Heiberger, and Loken 2010; Wong 2013). Junco, Heiberger, and Loken (2010) found that, when used in educationally relevant ways, Facebook and Twitter can facilitate a culture of engagement between students who can then interact about academic and co-curricular issues. Rockinson-Szapkiw and Szapkiw (2011) likewise observed that, when aligned with lesson objectives, Twitter can be successfully used to both provide opportunities for classroom collaboration and to create engaging learning experiences. Other studies have measured students' attitudes towards the integration of various technologies into the classroom. Manochehri and Sharif (2010), for example, found that technology could be used to facilitate selfdirected learning among higher education students, which was the result of student beliefs that the task was relevant and would benefit them in the future.

Each of the above approaches is built on the widely held, yet largely contested belief, that students who attend today's schools are different from those of previous years because the use of technology is altering not only their learning styles, but also their strengths and preferences (Dede 2007; Shapley et al. 2011; Smolin and Lawless 2007). These studies presuppose that, in order to engage this cohort of increasingly 


\section{A. Antonio and D. Tuffley}

tech-savvy students, it is beneficial, if not necessary, to incorporate the tools and technologies that students are already using in their everyday lives into the classroom. Although the term 'digital native' [A phrase coined by Prensky (2001) to describe a new group of students who are 'native speakers' of the digital language of computers and the Internet] has been met with considerable opposition, it is undoubtedly true that the vast majority of students transitioning directly from school to university in 2013 have never known a life without the Internet. It is however important to distinguish between technical competence and knowing how to leverage digital platforms for educational purposes and future employability. Thus we attempted to extend prior research by focusing on how the integration of technology into the curriculum could be combined with a goal-setting approach for the purpose of increasing student engagement.

\section{Purpose of study}

The current study builds on both the importance of cultivating motivation and engagement through goal setting among higher education students and the integration of technology into the classroom. By integrating the digital curation tool Scoop.it (a free, web-based service that the authors have no commercial interest in) into the curriculum, and setting a task that required students to curate content on a selfselected topic in the information technology (IT) industry that they were interested in pursuing as a career, it was reasoned that student engagement would be engendered. The engagement and goal-setting strategy employed for this research encouraged students to reframe study from being an end in itself to being a means to an end. Rather than seeing their future as an endless series of assignments and exams, it was anticipated that the students would see themselves moving purposefully towards their ideal career.

\section{Method}

\section{Participants}

At the commencement of the study, there were 258 first year undergraduate students enrolled in a first semester Communications for ICT course, which was offered across a metropolitan university's three campuses. Participation in the survey was optional and no additional course credit was available for participating students, and no incentive was offered. This may explain, at least in part, why only 84 out of a possible 258 students completed the survey questionnaire.

\section{Measures}

The researchers, using the survey-building tool Qualtrics, developed a 21-item questionnaire, which was modelled on the validated National Survey of Student Engagement (NSSE) instrument. Modifications were made to assess the students' engagement with the digital curation tool Scoop.it specifically, rather than their general levels of academic engagement. The survey was approved by the ethics committee and distributed to the Communications for ICT students via email. However, ethics approval did not extend to the archiving of the students' Scoop.it materials or their social media posts. Due to the constantly changing nature of the Internet, and the possibility that existing platforms such as Scoop.it could be closed at 
any time, it could not be guaranteed that the data could be stored and/or maintained for the requisite period of time. Moreover, the students were not required to keep their Scoop.it accounts active following completion of the assessment task, which would have resulted in the loss of key data.

The survey captured demographic information and included both multiple-choice items and open-ended questions (For a full list of questions, please refer to Appendix 1).

\section{Procedures}

\section{Reflective goal setting}

In order to encourage students to think about their career goals, rather than focusing on the immediate assessment task, the course lecturer invoked a reflective goalsetting technique. At the beginning of each lecture, for a 4-week period, the students were asked to consider 'where you are now and where you would like to be in 5-10 years'. In successive lectures the same question was asked but in a slightly different way, such as 'do you have an idea of what your ideal future career looks like?' and 'in an ideal world, what would you be doing 5 years from now?'.

In conjunction with this technique, the students were shown carefully selected YouTube videos or TED talks in which high-performing technologists were featured or a cutting-edge technology showcased. The self-reflective goal strategy and exposure to high-performing IT role models was designed to inspire and motivate the students to pursue a similar career path.

\section{Two-part assessment task}

In addition to the rhetorical goal-setting strategy, a two-part assessment task was given to the students. This required students to research and explore their ideal career. Part 1 of the assessment task involved researching an area of ICT that they were interested in pursuing in the future. The students were presented with a comprehensive list of possible topics, which included emerging areas of technology, such as artificial intelligence and Google glass, among many. The students also had the option of choosing a topic of their own devising. In order to reinforce the goalsetting technique, the lecturer emphasised the importance of choosing a topic that was interesting, relevant, and useful for the students' future career pursuits. The integration of technology was also introduced during this phase. The students were required to use the digital curation platform Scoop.it to curate the online resources they found in the course of their research. They were shown how to use Scoop.it during the first lecture of the course and additional video tutorials were available on the course Learning Management System. Scoop.it allows users to insert relevant keywords pertaining to their chosen topic and the platform subsequently trawls the web and generates content based on these keywords. The students then play an active editorial role by scrolling through the suggested content and selecting the content they want to publish on their personal page.

The students had to collect a minimum of five pieces of digital content (Scoop.it trawls web-based resources such as blogs, wikis, RSS feeds, etc. based on a key-word search algorithm) pertaining to their chosen topic area, justify the inclusion of this content with commentary and submit the Scoop.it URL to the course lecturer by the assignment due date. Part 2 of the assessment was an essay-writing task. Using their curated resources as inspiration, the students submitted a 1,000 word essay based on 
their chosen topic or, alternatively, on current trends in the IT industry that were likely to be influential in the next 5-10 years. The essay was due 2 weeks after the Scoop.it curation task.

\section{Survey}

At completion of the two-part, progressive assessment task, a survey questionnaire was emailed to all students enrolled in the Communications for ICT course, although completion of the survey was voluntary. As the students provided no identifying information, it was not possible for the lecturer to identify who had or had not participated in the survey. The anonymous nature of the survey mitigated any possibility of students feeling pressured into completing the survey, due to anxiety about the repercussions of not responding. As such, the grade the students' received for the assessment task was not influenced by whether or not they responded to the survey. The survey was designed to assess the students' engagement with the Scoop.it task and to ascertain the extent to which students believed the task had helped them clarify their career goals.

\section{Data analysis}

A report of survey responses was generated using the Qualtrics software. This report contained information regarding the minimum and maximum values, mean, variance, standard deviation and total responses for each of the multiple-choice items. Content analysis, via NVivo, was undertaken for open-ended questions in order to identify themes relating to student engagement (which included the use of words such as 'fun' and 'enjoyable') or the development of career goals (which included words such as 'future' or 'career'). According to Gillham (2000), the essence of content analysis is identifying the substantive statements in contiguous blocks of text. In its simplest form, content analysis involves counting the number of occurrences per category. Given the specific focus on student engagement and goal setting in this paper, this approach was deemed logical and participants' responses were thus categorised and occurrences of each category calculated. Although the questionnaire contained 21 items, data analysis for the current study was limited to items of direct relevance to student engagement and/or career goals.

In addition to demographic variables, data regarding the frequency of Scoop.it use (survey question 9), networking behaviour (survey question 10), experience of using Scoop.it (survey question 11), obstacles encountered and benefits of using Scoop.it (survey questions 12 and 13 respectively) were analysed. For Likert-scale items (survey questions 16 and 17), responses of Strongly Agree and Agree and Strongly Disagree and Disagree were conflated. For open-ended survey questions 18 and 21 , content analysis was conducted to ascertain key themes pertaining to engagement and/or career aspirations. The Scoop.it URLs were also analysed to verify frequency of login.

\section{Results}

The survey was emailed to 258 students enrolled in the Communications for ICT course. A total of 85 responses were received yielding a participation rate of $33 \%$. This response rate is consistent with those generally received in the University's 
Student Evaluation of Course \& Teaching survey, which is administered to each course at the end of each semester. Moreover, this response rate is typical of online surveys. In a review of eight surveys, Nulty (2008) found that online surveys received a response rate of $33 \%$, compared to $56 \%$ for paper-based surveys.

\section{Demographic variables}

Seventy-nine percent of the sample identified as male and $21 \%$ as female. Sixty-three percent of survey respondents were born between 1991 and 1996 (under the age of 22 at time of survey completion) and $70 \%$ of the cohort were under the age of 25 . Ninety-one percent of participants were enrolled in an on-campus mode of study and for $70 \%$ this was the first higher education degree they had enrolled in.

\section{Frequency}

The participants were asked to indicate how frequently they had used Scoop.it during the completion of Part 1 of the assignment. Four options were given: once a day, three times a week, once a week and none of these. Table 1 shows the frequency with which students used Scoop.it.

Participants who selected 'none of these' were asked in a follow-up survey question to indicate how often they used Scoop.it. Respondents reported that that they visited their account once, collected the minimum five pieces of content required to complete the assignment, and did not return to the platform again. Analysis of the students' Scoop.it URLs confirmed this finding. The dates of Scoop.it postings were recorded on the Scoop.it platform, which confirmed that some students continued to return to their Scoop.it account throughout the assessment task.

\section{Networking}

The participants were presented with a series of seven statements that were designed to assess how they networked with other students and the wider community during the Scoop.it task. Of note, $71 \%$ of participants indicated that they re-scooped content (searched for content from other users with similar topics) from other users, whereas $33 \%$ did not suggest content (share content they curated with others curating similar topics) to other users. A further $13 \%$ of participants elected to use the Facebook and/ or Twitter functionality to share the content they curated.

\section{Usability, obstacles and benefits (questions 12, 13 and 15)}

Seventy-four percent of participants indicated that the Scoop.it platform was intuitive and easy to use. A further 19\% said that it was easy to use after they had used it a couple of times. Seventy-five percent of participants did not experience any obstacles and/or barriers and $13 \%$ who said they experienced problems suggested that it was

Table 1. Frequency with which participants used Scoop.it.

Once a day 


\section{A. Antonio and D. Tuffley}

due to a lack of understanding of the task, rather than a difficulty with the technology itself. Participants were asked to indicate what the benefits and/or advantages of using Scoop.it were. They were presented with a range of options on a multiple item scale, which meant they could choose more than one answer. Sixty-eight percent of respondents said that engaging with their chosen assignment topic was the greatest benefit of Scoop.it

\section{Likert-scale items}

The participants were asked: 'To what extent do you agree or disagree with the following statements?' Responses of Strongly Agree and Agree and Strongly Disagree and Disagree were conflated in order to ascertain the number (percentage) of participants who agreed or disagreed with a given statement. Responses of 'neither agree nor disagree' were excluded from the results. A total of 85 responses were received. Table 2 shows the percentage of respondents who agreed or disagreed with a series of statements designed to ascertain the extent to which the students' believed the Scoop.it task had helped them clarify their career goals. Table 3 shows the percentage of respondents who agreed or disagreed with a series of statements designed to ascertain the extent to which the students' valued and/or enjoyed the Scoop.it task.

\section{Open-ended questions}

The participants were asked: Do you have any additional feedback or comments you would like to share with regards to the quality of the Scoop.it assessment task? Content analysis was conducted and the responses (a total of 20) were grouped according to category.

\section{Frustration}

Of the 20 responses received, the majority related to frustration at having to use peerreviewed resources for Part 2 of the assignment, which were not (or rarely) automatically generated via the Scoop.it search engine. One participant noted that there were 'far too many worthless links from the search function .... Also, none of

Table 2. To what extent do you agree or disagree with the following statements.

\begin{tabular}{lcc}
\hline Statement & $\begin{array}{c}\text { Strongly agree/ } \\
\text { agree (\%) }\end{array}$ & $\begin{array}{c}\text { Strongly disagree/ } \\
\text { disagree (\%) }\end{array}$ \\
\hline $\begin{array}{l}\text { The use of Scoop.it has helped me clarify my career } \\
\text { goals }\end{array}$ & 45 & 30 \\
$\begin{array}{l}\text { The use of Scoop.it has helped me determine the areas } \\
\text { of ICT I am interested in }\end{array}$ & 46 & 19 \\
$\begin{array}{l}\text { As a result of using Scoop.it, I have discovered areas } \\
\text { of ICT that I was previously unaware of }\end{array}$ & 56 & 21 \\
$\begin{array}{l}\text { I learned more from using Scoop.it than I would have } \\
\quad \text { rom writing an essay alone }\end{array}$ & 54 & 20 \\
$\begin{array}{l}\text { I was motivated to use Scoop.it to complete the } \\
\text { assessment task }\end{array}$ & 65 & 13 \\
\begin{tabular}{l} 
I enjoyed using Scoop.it for the assessment task \\
\hline
\end{tabular}
\end{tabular}


Table 3. To what extent do you agree or disagree with the following statements.

\begin{tabular}{lcc}
\hline Statement & $\begin{array}{c}\text { Strongly agree/ } \\
\text { agree (\%) }\end{array}$ & $\begin{array}{c}\text { Strongly disagree/ } \\
\text { disagree (\%) }\end{array}$ \\
\hline $\begin{array}{l}\text { The use of Scoop.it enhanced my learning } \\
\text { experience }\end{array}$ & 60 & 14 \\
I would take another course with a Scoop.it & 69 & 11 \\
$\quad$ component & 63 & 19 \\
I would use Scoop.it in another situation & 62 & 15 \\
I will be able to use Scoop.it in my future studies & 65 & 15 \\
Scoop.it is a valuable research tool & 43 & 24 \\
I will continue to use my Scoop.it account after the & & \\
$\quad$ assessment task is completed &
\end{tabular}

the sources were peer-reviewed on Scoop.it yet we were apparently meant to only use peer-reviewed sources for the essay'. Similarly, another respondent said 'while scoop.it is a nice way to find web content ... and for collating things that I have found, it's not useful when peer-reviewed references are required'. A participant who expressed frustration that 'we weren't allowed to use any of the sources we had discovered made the entire Scoop.it process rather pointless', reiterated the issue of having to use peer-reviewed resources exclusively.

\section{Engagement and clarification of goals}

Four of the comments pertained to either student engagement with the Scoop.it task or clarification of their career goals. One respondent said that 'I really enjoyed using Scoop.it for the assessment task', while another said that 'I really enjoyed using Scoop.it' generally. Another participant thanked the researchers for 'providing us with a more entertaining assessment. I am the kind of student who doesn't like writing tasks and this made it a lot more enjoyable .... In terms of the effectiveness of the task for helping students clarify their career goals, it was noted that '... the Scoop.it assignment made me think about my future in ICT ...'.

\section{Benefits of using scoop.it}

The participants were asked: 'Please let us know if there were any other benefits or advantages to using Scoop.it'. Twenty responses were received, with most comments comparing the relative merit of the Scoop.it task to a conventional annotated bibliography. Participants indicated their preference for this more interactive task and were appreciative of the opportunity they had been given to use their ICT skills in educationally relevant ways: 'I found it very helpful in engaging with my topic. I learn so much I had no idea about and I also felt (dare I say) excited about it'. Another participant said '... I was genuinely interested in the sources that were recommended, rather than trying to find sources to fill the word count for the assignment'.

\section{Discussion}

This study sought to understand how a goal-setting strategy, in conjunction with the integration of technology into the curriculum, could be used to cultivate engagement among higher education students. Our findings were consistent with prior research 
regarding the importance of formulating clearly defined goals (Locke and Latham 1990; Oyserman 2008; Perry, Liu, and Pabian 2010) and academic relevancy (Andriessen, Phalet, and Lens 2006; Greene et al. 2004; Orthner et al. 2012; Tan 2007) for increasing engagement. Moreover, as expected, based on past research in the area (Ebner et al. 2010; Junco, Heiberger, and Loken 2010; Manochehri and Sharif 2010; Wong 2013), the integration of technology into the curriculum was appreciated by the students and contributed, in the current study, to perceptions of relevance of the task to the students' future activities.

The results suggest that the participants in this study engaged with the task because it allowed them to utilise the latest digital technologies. This may have been due to the fact that $70 \%$ of this cohort (who were under the age of 25 ) were, for want of a better term, digital natives. Alternatively, in support of past research (Arnold and Mackenzie 1992), the participants were engaged by the task because it enabled them to utilise the digital literacy skills they already possess, plus it was relevant to their career goals. As ICT students, they would no doubt expect to use technology throughout their studies, which was borne out by their appreciation at being given a more interactive assessment task than a traditional essay: 'Thanks for providing us with a more entertaining assessment'.

Moreover, our findings reiterate and emphasise the importance of self-directed learning (Manochehri and Sharif 2010) for cultivating student engagement. The results of this study suggest that, in many cases, the participants did more than was required to complete the assignment. The frequency with which the participants engaged with the Scoop.it platform, re-scooped content from others and used the social networking sites to share content suggests that they were motivated to explore the additional functionality of Scoop.it and to integrate it with their existing social media accounts. The use of Facebook and/or Twitter was not a requirement of the assessment task and yet some participants elected to use these sites for educational networking (Antonio and Tuffley 2014). Furthermore, in order to complete the assessment task, it would have been possible, at a minimum, to log into Scoop.it once, curate five resources and submit the URL to the course lecturer. However, it was found that the majority of participants $(86 \%)$ checked their Scoop.it accounts repeatedly throughout the assessment period and even, in some cases, following assignment submission. Moreover, this occurred despite the fact that the students were not allowed to use their curated resources for the formal essay task (unless they found peer-reviewed materials), and that they were required to conduct an additional literature search in order to submit an essay that met the academic standards required by the university.

Our findings suggest that the innovative combination of (1) goal setting and (2) the integration of technology is a successful engagement strategy that is relatively simple to implement and is potentially applicable across a wide range of disciplines.

The current project provides a solid foundation for a longitudinal study to be conducted over at least a 3-year period in which the current cohort of students are surveyed again in their final semester, just prior to leaving university and entering the IT industry. To survey at least one cohort at the beginning and end of their university studies is desirable, in order to ascertain whether or not their career goals have altered. It was anticipated that the opportunity to thoroughly research and curate content around an area of IT they were interested in would give the students an avenue and goal to work towards. And while such a survey would not allow us to determine whether it was the Scoop.it task itself that had motivated the students to completion of their studies, it would be useful to explore whether the assessment task 
had encouraged the students to pursue or in fact rethink their chosen career path. Two or three such cohorts would provide a more comprehensive set of results with which to draw conclusions. Such a longitudinal study is planned, with the personnel and resources available to conduct it.

The limitations of this project include a relatively low (33\%) response rate to the survey. This figure is consistent with the historic response rates to surveys generally by students at this university, at least over the previous 5-7 years. This response rate has nonetheless yielded informative and actionable data in relation to student evaluations of courses in the past, so the response rate in this project is arguably useful for the purposes of evaluating the engagement strategy.

\section{Conclusion}

Given the empirically derived quantitative and qualitative data, there is evidence to support the argument that the goal-setting strategy used in this project helps students to clarify their future career. This clear vision of an exciting future naturally reinforces a career goal that the student is encouraged to revisit often and in which to invest emotional energy. In implementing the goal-setting approach, the lecturer used the ageold rhetorical technique of repeatedly making a comparison between a person's current state and a more desirable future state. Examples of this practice abound, from Martin Luther King's 'I have a Dream' speech, to Steve Jobs launching the first iPhone. It works because people tend to have a biased belied that the grass is greener on the other side. However, using this rhetorical device is not essential to the process. Other lecturers will have their own way of achieving the same effect. The evidence indicates that the Scoop.it task, in conjunction with the goal-setting approach, is an effective engagement strategy. Further research is however required to determine whether or not the assessment task has had any lasting influence on this cohort of students' career choices. This will be the subject of a later project and the topic of a later paper.

\section{References}

Andriessen, I., Phalet, K. \& Lens, W. (2006) 'Future goal setting, task motivation and learning of minority and non-minority students in Dutch schools', British Journal of Educational Technology, vol. 76, no. 4, pp. 827-850.

Antonio, A. \& Tuffley, D. (2014) 'Creating educational networking opportunities with Scoop.it', Journal of Creative Communications, vol. 9, no. 2, pp. 185-197.

Arnold, J. \& Mackenzie Davey, K. (1992) 'Beyond unmet expectations: a detailed analysis of graduate expectations at work during the first three years of their careers', Personnel Review, vol. 21, no. 2, pp. 45-86.

Astin, A. W. (1999) 'Student involvement: a developmental theory for higher education', Journal of College Student Development, vol. 40, no. 5, pp. 518-529.

Bandura, A. (1982) 'Self-efficacy mechanism in human agency', American Psychologist, vol. 37, no. 2, pp. $122-147$.

Chiu, L. (1990) 'The relationship of career goals and self-esteem among adolescents', Adolescence, vol. 25, no. 99, pp. 593-597.

Dede, C. (2007) 'Reinventing the role of information and communications technologies in education', in Information and Communication Technologies: Considerations of Current Practice for Teachers and Teacher Educators, eds L. Smolin, K. Lawless \& N. Burbules, Blackwell, Malden, MA, pp. 11-38.

Ebner, M., et al., (2010) 'Microblogs in higher education - a chance to facilitate informal and process-oriented learning', Computers and Education, vol. 55, no. 1, pp. 92-100.

Gillham, B. (2000) Case Study Research Methods, Continuum, London. 


\section{A. Antonio and D. Tuffley}

Greene, B., et al., (2004) 'Predicting high school students' cognitive engagement and achievement: contributions of classroom perceptions and motivation', Contemporary Educational Psychology, vol. 29, no. 4, pp. 462-482.

Hull-Blanks, E., et al., (2005) 'Career goals and retention-related factors among college freshmen', Journal of Career Development, vol. 33, no. 1, pp. 16-30.

Junco, R., Heiberger, G. \& Loken, E. (2010) 'The effect of Twitter on college student engagement and grades', Journal of Computer Assisted Learning, vol. 27, no. 2, pp. 119-132.

Lessard, A., et al., (2014) 'Analysing the discourse of dropouts and resilient students', The Journal of Educational Research, vol. 107, no. 2, pp. 103-110.

Locke, E. \& Latham, G. (1990) A Theory of Goal Setting and Task Performance, Prentice Hall, Englewood Cliffs, NJ.

Manochehri, N. \& Sharif, K. (2010) 'A model-based investigation of learner attitudes towards recently introduced classroom technology', Journal of Information Technology Education: Research, vol. 9, pp. 31-52.

Nauta, M. (1997) 'Women in mathematics, science, and engineering college majors: a model predicting career aspirations, based on ability, self-efficacy, role model influence, and role conflict', Dissertation Abstracts International, vol. 58, p. 3355.

Nulty, D. (2008) 'The adequacy of response rates to online and paper surveys' what can be done? Assessment and Evaluation in Higher Education, vol. 33, no. 3, pp. 301-314.

Olson, J. (2013) 'Opportunities, obstacles, and options: first-generation college graduates and social cognitive career theory', Journal of Career Development, vol. 41, pp. 199-217.

Orthner, D. (2007) 'Public schools: building capacity for hope and opportunity', in Ending Poverty: How to Restore the American Dream, eds J. Edwards, M. Crain \& A. Kalleberg, New Press, Chapel Hill, NC.

Orthner, D., et al., (2012) 'Improving middle school student engagement through careerrelevant instruction in the core-curriculum', The Journal of Educational Research, vol. 106, no. 1 , pp. $27-38$.

Oyserman, D. (2008) 'Possible selves: identity-based motivation and school success', in Self-Processes, Learning, and Enabling Human Potential, eds H. Marsh, R. Craven \& D. McInerney, Information Age Publishing, Charlotte, NC, pp. 269-289.

Perry, J. (2008) 'School engagement among urban youth of colour', Journal of Career Development, vol. 34, no. 4, pp. 397-422.

Perry, J., Liu, X. \& Pabian, Y. (2010) 'School engagement as a mediator of academic performance among urban youth: the role of career preparation, parental career support, and teacher support', The Counselling Psychologist, vol. 38, no. 2, pp. 269-295.

Prensky, M. (2001) 'Digital natives, digital immigrant', On the Horizon, vol. 9, no. 5, pp. 15-24.

Radloff, A. (2012) 'Findings from the Australasian survey of student engagement', ACER [online], Available at: http://www.acer.edu.au/ausse

Rockinson-Szapkiw, A. \& Szapkiw, M. (2011) 'Engaging higher education students through tweeting', Faculty Publications and Presentations, Paper 183 [online], Available at: http:// digitalcommons.liberty.edu/educ_fac_pubs/183

Shapley, K., et al., (2011) 'Effects of technology immersion on middle school students' learning opportunities and achievement', The Journal of Educational Research, vol. 10, no. 5, pp. $299-315$.

Smolin, L. \& Lawless, K. (2007) 'Technologies in schools: stimulating a dialogue', in Information and Communication Technologies: Considerations of Current Practice for Teachers and Teacher Educators, eds L. Smolin, K. Lawless \& N. Burbules, Blackwell, Malden, MA, pp. 1321-1335.

Tan, K. (2007) 'Conceptions of self-assessment: what is needed for long-term learning?', in Rethinking Assessment in Higher Education: Learning for the Longer Term, eds D. Boud \& N. Falchikov, Routledge, New York, pp. 114-127.

Tuffley, D. \& Antonio, A. (2013) 'First year engagement and retention: a goal setting approach', Journal of Information Technology Education: Innovations in Practice, vol. 12, pp. 239-251.

Wong, L. (2013) 'Student engagement with online resources and its impact on learning outcomes', Journal of Information Technology Education: Innovations in Practice, vol. 12, pp. $129-146$.

Wright, S., Jenkins-Guarnieri, M. \& Murdock, J. (2012) 'Career development among first year college students: college self-efficacy, student persistence and academic success', Journal of Career Development, vol. 40, no. 4, pp. 292-310. 


\section{Appendix 1}

Modified version of the National Survey of Student Engagement (NSSE) Instrument

Question 1: Do you wish to proceed?

Question 2: What is your gender?

Question 3: What year were you born?

Question 4: Are you registered as an on-campus or off-campus student?

Question 5: Did you finish secondary school in the last 2 years?

Question 6: Have you been employed in the workforce for more than 3 years?

Question 7: What is the name of the course you are enrolled in?

Question 8: Is this the first degree you have enrolled in at a higher education institution?

Question 9: Did you use Scoop.it as part of the Communications for ICT assignment?

Question 10: Which statement best describes how frequently you engaged with Scoop.it?

- I checked my Scoop.it account every day

- I checked my Scoop.it account at least three times a week

- I checked my Scoop.it account once a week

- None of these (Please specify)

Question 11: Which statement best describes how you networked with others on Scoop.it? (Check all that apply)

- I re-scooped content from other Scoop.it users

- I suggested content from other Scoop.it users

- I re-scooped content from other Scoop.it users and suggested content to other Scoop.it users

- I used Facebook and/or Twitter to share content with others

- I did not re-scoop other Scoop.it user's content

- I did not suggest content to other Scoop.it users

- None of these (Please specify)

Question 12: Which statement best describes your experience if using Scoop.it

- I found Scoop.it intuitive and easy to use

- I found Scoop.it easy to use after I had used it several times

- I found it difficult to set up a Scoop.it account

- None of these (Please specify)

Question 13: What was the primary obstacle, if any, you encountered when using Scoop.it?

- Technological or connectivity problems

- Lack of support

- Lack of understanding of task

- Insufficient guidance

- I did not experience any barriers

Question 14: Please let us know about any problems or challenges you experienced when using Scoop.it

Question 15: What are the benefits of Scoop.it? (Check all that apply)

- Learning how to assess the value of web-based content

- Learning how to use a new digital tool

- Engaging with my topic

- Using digital content in my essay

- Networking with other students

Question 16: Please let us know if there were any other benefits or advantages of using Scoop.it 
Question 17: To what extent do you agree or disagree with the following statements?

- The use of Scoop.it helped me develop my critical thinking skills

- As a result of using Scoop.it, I feel I can make judgments about the value of digital content

- As a result of using Scoop.it, I feel I can synthesise and organise ideas and information

- As a result of using Scoop.it, I feel I can make judgments about the currency of information

- As a result of using Scoop.it, I feel I can analyse content in depth

- As a result of using Scoop.it, I feel able to cite web-based content

- As a result of using Scoop.it, I feel confident in my ability to use web-based content in my assignments

- As a result of using Scxoop.it. I feel I can distinguish between good and bad web-based content

Question 18: To what extent do you agree or disagree with the following statements?

- The Scoop.it assessment task has helped me network with other students in this subject

- Scoop.it has helped me network with other students

- The Facebook function on Scoop.it enabled me to share content I found with others

- The Twitter function on Scoop.it enabled me to share content I found with others

- The social media functions on Scoop.it helped me network with other students

Question 19: To what extent do you agree or disagree with the following statements?

- The use of Scoop.it helped me clarify my career goals

- The use of Scoop.it helped me determine the areas of ICT I am interested in

- As a result of using Scoop.it, I have discovered areas of ICT that I was previously unaware of

- I learned more from using Scoop.it than I would have from writing an essay alone

- I was motivated to use Scoop.it to complete the assessment task

- I enjoyed using Scoop.it for the assessment task

Question 20: To what extent do you agree or disagree with the following statements?

- The use of Scoop.it enhanced my learning experience

- I would take another course with a Scoop.it component

- I would use Scoop.it in another situation

- I will be able to use Scoop.it in my future studies

- Scoop.it is a valuable research tool

- I will continue to use my Scoop.it account after the assessment task is completed

Question 21: If you have any additional comments or feedback that you would like to share regarding the quality of the Scoop.it assessment task, please type them below. 